\title{
To Correlate Serum Ferritin Levels with Clinical Outcome in Covid-19 Patients
}

\author{
Avinash Hanbe Rajanna ${ }^{1}$, Ravi Krishnegowda ${ }^{2}$, Rohith Maraludevanapura Govindaiah ${ }^{3}$ \\ ${ }^{1}$ Assistant Professor, ${ }^{2}$ Professor and Head, ${ }^{3}$ Post-Graduate trainee, Department of General Medicine, Bangalore \\ Medical College and Research Institute, Bangalore, Karnataka, India
}

Background: COVID-19 a pandemic, affecting worldwide causing significant morbidity and to some extent mortality needs to be evaluated and urgently identify reliable predictors of disease severity and outcome. The fatal outcomes by COVID-19 are accompanied by cytokine storm syndrome. The cytokine storm is determined by serum ferritin. Aims and Objective: To determine the role of Serum ferritin in assessing the severity and outcome of COVID-19. Materials and Methods: A single-center, cross-sectional, observational study was conducted among SARS-CoV-2 infected patients from March 2020 to May 2020. The diagnosis was confirmed by real-time polymerase chain reaction (RT-PCR). Serum ferritin levels were compared with the treatment outcomes of COVID-19 positive patients. Results: A total of 1977 COVID-19 patients were studied. The mean age was $43.89 \pm 15.58$ years and had male preponderance of $61.56 \%$ of the total subjects. The mean serum ferritin levels among recovered and expired patients were $1225.6 \pm 2502.91 \mathrm{ng} / \mathrm{ml}$ and $285.71 \pm$ $391.99 \mathrm{ng} / \mathrm{ml}$, respectively. Conclusion: Serum ferritin was markedly increased in COVID-19 patients who could not survive as compared to the patients who finally recovered from the infection, proving it as a useful marker for assessing the severity of COVID-19.

Key words: COVID-19; Serum ferritin; cytokine storm

\section{Access this article online}

Website:

http://nepjol.info/index.php/AJMS DOI: 10.3126/ajms.v12i5.34371

E-ISSN: 2091-0576

P-ISSN: 2467-9100

Copyright (c) 2021 Asian Journal of Medical Sciences

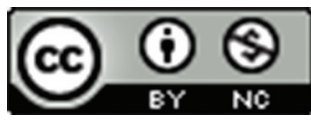

This work is licensed under a Creative Commons Attribution-NonCommercial 4.0 International License.

\section{INTRODUCTION}

COVID-19 infection, which first reported as a cluster of pneumonia from Wuhan, China, in December 2019, has rapidly emerged as a global pandemic. ${ }^{1}$ During the early course of the pandemic, Italy had the highest infection burden and India remained much less affected with corresponding mortality rates of $14.24 \%$ and $3.03 \%{ }^{2}$ The total cases in India has now crossed 10.5 million mark and officially confirmed deaths being 1,51,727, according to the Health Ministry data published on Jan $14,2021 .{ }^{3}$

This condition is associated with high morbidity, leading to significant burden on healthcare infrastructure and resources. The associated fatality rate is also higher than other respiratory viral infections. Hence, it is necessary to identify reliable predictors of disease severity and mortality for careful allocation of healthcare resources and to enable earlier clinical intervention to improve clinical outcomes.

Various biomarkers are being investigated for their role in determination of severity and prognosis in COVID-19. Elevated levels of ferritin, indicate the viral or bacterial load in the body. Ferritin is raised when activating macrophages secrete cytokines, causing a cytokine storm, which can be a sign of severe disease. ${ }^{4}$ As severe COVID-19 is seen associated with cytokine storm, ferritin levels can be used as a marker to assess the same.

In this study, we assessed the correlation between serum ferritin and severity and mortality of COVID-19 positive patients. We aimed to evaluate the serum concentrations of ferritin and correlate it with the clinical outcomes. 


\section{MATERIALS AND METHODS}

This was an observational cross sectional, study conducted among patients admitted under medicine department between March to May 2020 at Victoria hospital, Bangalore Medical College and Research Institute, Bangalore, Karnataka, India. Approval and clearance were obtained from the institutional ethics committee on 18/04/2020-BMCRI/PS/02/2020-21. The study included patients aged $\geq 18$ years of both the gender, diagnosed with COVID-19 infection by RT-PCR technique using ABI/ Thermofischer - Taqppath technique. The study excluded patients $<18$ years and those not willing to provide signed informed consent prior to the study.

Sample size estimation:

$$
\begin{gathered}
\mathrm{N}=\frac{\mathrm{Za}^{2} \sigma^{2}}{\mathrm{~d}^{2}} \\
\mathrm{~N}=\frac{1.92^{2} * 400^{2}}{4 \% \text { of mean }}=1676.07
\end{gathered}
$$

Case record form with follow-up chart was used to record the demographic data, and duration and clinical features of the disease. Patients data like clinical symptoms and incidence of co-morbidities like hypertension, diabetes, and metabolic disorders like renal, cardiac and respiratory disorders were collected. All the selected participants were followed up until discharge or death. A blood sample was collected from all the patients and sent for laboratory investigations, exclusively serum ferritin levels were compared with the treatment outcomes of all the patients. The serum ferritin level was determined by electrochemiluminescence immunoassay (ECLIA) with Roche COBAS analyzer system. It was compared between the patients who recovered and got discharged and the patients who died during the course of the hospital.

As per the first discharge policy released by the state government, the patients were discharged after 14 days, if 2 consecutive throat/nasopharyngeal swabs taken $24 \mathrm{hrs}$ apart were negative for SARS-CoV-2 RNA done using RTPCR technique. If positive, test was repeated after $72 \mathrm{hrs}$. As per the revised discharge policy dated 26/05/2020, all mild and asymptomatic patients were discharged only after a repeat RT-PCR technique for SARS-CoV-2 RNA was negative, conducted 7 days after the first test. If positive, test was repeated after $72 \mathrm{hrs}$. As per the third discharge policy dated 23/06/2020, patients who had mild and moderate symptoms were discharged after 10 days without throat/nasopharyngeal swab test for COVID-19 and for severe patients, $14^{\text {th }}$ day discharge policy based on negative swab test was adopted and those who were positive, the tests were repeated every $3^{\text {rd }}$ day till obtaining a negative result. The demographics and clinical outcome were further correlated.

Statistical analysis was carried out using software $\mathrm{R}$ version 3.6.0, 2019 Vienna, Austria. Continuous variables were expressed as means and standard deviation and categorical variables were presented as counts and percentages. Patients were grouped as survival and death. Different parameters were compared between the groups using t-test for continues and chi-square test for categorical data. The optimal cut points were estimated for significant continuous variables using receiver operating curve (ROC) analysis. Multiple regression analysis was carried out and odds ratio with confidence interval $(\mathrm{CI})$ were estimated to determine the effect of significant factors on outcome death and survival. For evaluating the mean days of viral clearance, many mild and moderate cases were not considered due to the implementation of the revised third discharge policy. $\mathrm{P}$ value $<0.05$ was considered as statistically significant.

\section{RESULTS}

The study considered 2000 patients admitted to Victoria hospital, Bangalore under medicine department and was diagnosed positive for COVID-19. Thirty-three patients were referred to different hospitals due to various reasons. Remaining 1977 patients were included in the study. All the patients were categorized as 2 Groups- group 1: survived (1839-93.02\%) and group 2: succumbed to death (138-6.98\%) based on the outcome observed. Among 1977 patients, 1419 (71.78\%), 128 (6.48\%) and $428(21.65 \%)$ were under 10 days asymptomatic policy, $2^{\text {nd }}$ day swab discharge policy and $7^{\text {th }}$ day swab policy respectively.

The demographic and clinical characteristics of the patients were studied. The average age of the patients was $43.89 \pm 15.58$ years and the mean age of survival and death noted were $42.74 \pm 15.15$ years and $59.12 \pm 12.95$ years respectively, table 1 . It was seen that patients $>50$ years of age were less likely to survive (only $32 \%$ patients survived).

Out of 1977, patients male to female ratio was 1:0.62 showing male preponderance as shown in Figure 1.

Fever, dyspnea and cough were the major symptoms prevalent among patients who succumbed to death than in patients who survived. In the mortality group only $12 \%$ were asymptomatic, whereas it was around 50\% among survived subjects, Table 2 . 


\section{Table 1: Age distribution among the patients}

\begin{tabular}{|c|c|c|c|}
\hline AGE & Total $(n=1977)$ & Survived $(n=1839)$ & Succumbed to death $(n=138)$ \\
\hline Age (years) & $43.89 \pm 15.58$ & $42.74 \pm 15.15$ & $59.12 \pm 12.95$ \\
\hline \multicolumn{4}{|l|}{ Age Group } \\
\hline$<30$ years, $\mathrm{n}(\%)$ & 419(21.19) & 418(22.73) & $1(0.72)$ \\
\hline $30-39$ years, $n(\%)$ & $452(22.86)$ & $443(24.09)$ & $9(6.52)$ \\
\hline $40-49$ years, $n(\%)$ & $369(18.66)$ & 351(19.09) & $18(13.04)$ \\
\hline $50-59$ years, $n(\%)$ & $356(18.01)$ & $313(17.02)$ & $43(31.16)$ \\
\hline $60-69$ years, $n(\%)$ & 238(12.04) & 198(10.77) & $40(28.99)$ \\
\hline
\end{tabular}

Table 2: Symptoms at the time of admission among different groups

\begin{tabular}{lccc}
\hline Symptoms & Total $(\mathrm{n}=1 \mathbf{1 9 7 7})$ & Survived $(\mathrm{n}=1839)$ & Succumbed to death $(\mathrm{n}=138)$ \\
\hline Asymptomatic, $\mathrm{n}(\%)$ & $941(47.80)$ & $924(50.24)$ & $17(12.32)$ \\
Fever, $\mathrm{n} \%$ & $600(30.35)$ & $532(28.93)$ & $68(49.28)$ \\
Dyspnea, $\mathrm{n} \%$ & $361(18.26)$ & $275(14.95)$ & $86(62.32)$ \\
Cough, $\mathrm{n} \%$ & $558(28.22)$ & $489(26.59)$ & $69(30.00)$ \\
Sore throat, $\mathrm{n} \%$ & $132(6.68)$ & $124(6.74)$ & $8(5.80)$ \\
Myalgia, $\mathrm{n} \%$ & $207(10.47)$ & $192(10.44)$ & $15(10.87)$ \\
Head ache, $\mathrm{n} \%$ & $19(0.96)$ & $1(0.72)$ & $18(10.98)$ \\
Others, $\mathrm{n} \%$ & $89(4.50)$ & $80(4.35)$ & $9(6.52)$ \\
\hline
\end{tabular}

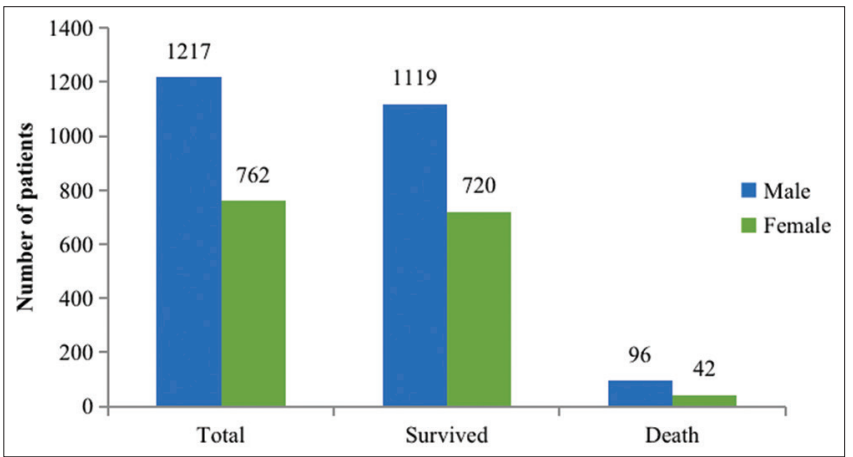

Figure 1: Sex distribution among the patients

Comorbidities of patients included in the study were noted as shown in Table 3.

Out of 1977 patients admitted, 140 patients required oxygen out of which 103 survived and 137 died. And 264 were admitted to ICU with 126 patients survived and 138 patients succumbed to disease (Table 4).

Mean serum ferritin among the patients who were included in the study was $341.36 \pm 747.79 \mathrm{ng} / \mathrm{ml}$. It was found that serum ferritin is high in those who succumbed to death when compared to those who survived $1225.6 \pm 2502.91$ $\mathrm{ng} / \mathrm{ml}$ and $285.71 \pm 391.99 \mathrm{ng} / \mathrm{ml}$ respectively and is statistically significant with $\mathrm{P}$ value of $<0.001$ (Table 5).

Cutoff points were determined for a continuous variable like serum ferritin through ROC analysis. Predicted cut off points, AUC, specificity, sensitivity and mean values noted for ferritin have been listed in Table 3. AUC for ferritin was $80.08 \%$ with cutoff point of $352 \mathrm{ng} / \mathrm{ml}$ along with the specificity and sensitivity of $76.32 \%$ and $74.6 \%$ respectively (Table 6 and Figure 2).

\section{DISCUSSION}

In concurrence with these findings, a study conducted by Saluja et al. in government medical college, Kota, Rajasthan has also observed increased male preponderance with majority being asymptomatic. ${ }^{5}$ In this study male to female ratio was 1:0.62 showing male preponderance.

The present study has demonstrated that the chances of survival are comparatively lower for patients $>50$ years of age. There is substantial literature evidence to validate the association between age-related COVID-19 severity and mortality. A meta-analysis and rapid review by Starke et al. have also reiterated the positive associated between increased age-related risk of COVID-19 disease severity, admission to ICU, and mortality. The increased risk per age year noted for disease severity was $2.7 \%{ }^{6}$ Similarly, a meta-analysis involving 611,583 subjects have reported that the mortality was $<1.1 \%$ in subjects aged $<50$ years and the largest increase was observed in patients between the age group of 60-69 years, as opposed to 50-59 years. ${ }^{7}$

Current study has noted fever, dyspnea and cough as the major symptoms prevalent among patients who succumbed to death when compared to those who survived. Zhang et al. have also evaluated the clinical characteristics of 82 deaths cases, laboratory confirmed as SARS-CoV-2 infection. The researchers have reported fever $(78.0 \%)$, cough (64.6\%), and shortness of breath (63.4\%) as the prominent symptoms reported in the succumbed victims. ${ }^{8}$ 
Table 3: Co-Morbidities of patients among different groups

\begin{tabular}{|c|c|c|c|}
\hline Comorbidities & Total $(n=1977)$ & Survived $(n=1839)$ & Succumbed to death $(n=138)$ \\
\hline None, $\mathrm{n}(\%)$ & $1105(55.89)$ & 1074(58.40) & $30(21.74)$ \\
\hline Diabetes only, n (\%) & 118(5.97) & $110(5.98)$ & $8(5.80)$ \\
\hline Hypertension only, n (\%) & $94(4.75)$ & $88(4.79)$ & $6(4.35)$ \\
\hline Diabetes or Hypertension with other complications, n (\%) & $417(21.09)$ & $344(18.71)$ & $73(52.90)$ \\
\hline Chronic Kidney disease, n (\%) & $25(1.26)$ & $17(0.92)$ & $8(5.80)$ \\
\hline Other, n (\%) & 219(11.08) & 196(10.66) & 13(9.42) \\
\hline
\end{tabular}

\begin{tabular}{|c|c|c|c|}
\hline Course in the hospital & Total $(n=1977)$ & Survived $(n=1839)$ & Succumbed to death $(n=138)$ \\
\hline Oxygen requirement, $\mathrm{n}(\%)$ & $140(7.08)$ & $103(5.6)$ & 137(99.28) \\
\hline ICU requirement, $\mathrm{n}(\%)$ & $264(13.35)$ & $126(6.85)$ & $138(100)$ \\
\hline
\end{tabular}

\begin{tabular}{|c|c|c|c|c|}
\hline Laboratory parameters & Total $(n=1977)$ & Survived $(n=1839)$ & Succumbed to death $(n=138)$ & P-value \\
\hline Ferritin (ng/ml) & $341.36 \pm 747.79$ & $285.71 \pm 391.99$ & $1225.6 \pm 2502.91$ & $<0.001$ \\
\hline
\end{tabular}

\begin{tabular}{lcccccc}
\multicolumn{6}{l}{ Table 6: Cut points, AUC, Specificity and Sensitivity noted for potential predictors } \\
\hline Predictor & Cut point & Survival & Death & AUC (\%) & Specificity (\%) & Sensitivity (\%) \\
\hline Ferritin $(\mathrm{ng} / \mathrm{ml})$ & 352 & $285.71 \pm 391.99$ & $1225.60 \pm 2502.91$ & 80.08 & 76.32 & 74.6 \\
\hline
\end{tabular}

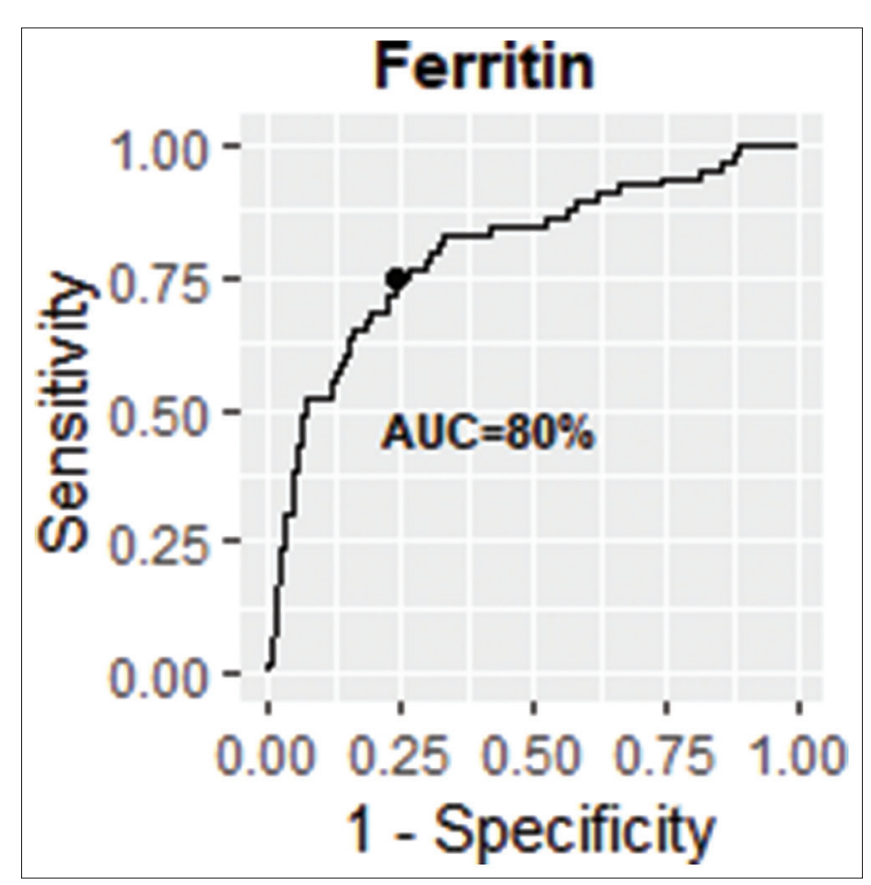

Figure 2: ROC Curve for different variables showing area under curve

The study Gupta et al. conducted in a tertiary care centre in India, has also noted fever and cough $(42.9 \%)$ as the most prominent symptoms, followed by headache, sore throat, and breathlessness. ${ }^{?}$

In this study it was found that serum ferritin was $285.71 \pm 391.99 \mathrm{ng} / \mathrm{ml}$ in group who survived compared to $1225.6 \pm 2502.91 \mathrm{ng} / \mathrm{ml}$ in group that succumbed to death which was statistically significant. The study by Hemanth Reddy et al. conducted in a tertiary care center in India, showed the serum activities of ferritin were markedly increased in COVID-19 patients who could not survive as compared to the patients who finally recovered from the infection. ${ }^{10}$

In the current mortality group, around $53 \%$ of the subjects had diabetes/hypertension with and around $6 \%$ of the subjects demonstrated chronic kidney disease as opposed to $0.92 \%$ in the survived group. A meta-analytic review focusing on developing countries including India has reported that the presence of comorbidities is linked to poor outcomes in COVID-19 subjects In concurrence with these findings data from Mexico has also identified CKD, hypertension, COPD, obesity and diabetes are associated with elevated mortality risk in COVID patients. ${ }^{11}$

Zhang et al. studied the clinical characteristics of 82 cases of death due to COVID-19 which showed that most of the patients who died had co-morbidities, most common being hypertension $(56.1 \%)$ and more than half of them who died were $>60$ years old. ${ }^{8}$

The present study holds significant relevance, as there is very limited literature evidence from the subcontinent correlating demographic data of COVID-19 patients with clinical profile and disease outcomes. Moreover, it sheds light on several significant findings, which would assist clinicians in screening, treatment decision and estimating 
the disease prognosis. Another strength of the study is good sample size, but the generalization of the findings is limited, as the study was carried out in a single center. The study has not evaluated the outcomes from treatment interventions. This was not considered, as no specific standard protocol was available at that point of pandemic for managing COVID-19 patients.

\section{CONCLUSION}

Increased activities of serum ferritin were observed among most COVID-19 patients. Serum ferritin was found to be elevated among the COVID-19 patients who could not survive the treatment as compared to the recovered patients. Therefore, serum concentrations of ferritin could be used as a prognostic marker in the management of COVID-19 patients which is easily available and cost effective too.

\section{ACKNOWLEDGEMENT}

Authors would like to thank all the residents and staffs of Department of Medicine, BMCRI and are grateful to all the patients who participated in the study.

\section{REFERENCES}

1. Pneumonia of unknown cause - China [Internet]. World Health Organization. 2021 [cited 2021 Jan 22]. Available from: https:// www.who.int/csr/don/05-january-2020-pneumonia-of-unkowncause-china/en/

2. COVID-19 Mortality Trends and Reporting [Internet]. Economic and Political Weekly. 2021 [cited 2021 Jan 22]. Available from: https://www.epw.in/journal/2020/37/commentary/covid-19mortality-trends-and-reporting.html
3. MoHFW. [Home] [Internet]. Mohfw.gov.in. 2021 [cited 2021 Jan 22]. Available from: https://www.mohfw.gov.in

4. Lu R, Qin J, Wu Y, Wang J, Huang S and Tian L. Epidemiological and clinical characteristics of COVID-19 patients in Nantong, China. J Infect Dev Ctries. 2020;14(05):440-446. https://doi.org/10.3855/jidc.12678

5. Saluja M, Pillai D, Jeliya S, Bauddh N and Chandel R. COVID 19Clinical Profile, Radiological Presentation, Prognostic Predictors, Complications and Outcome: A Perspective from the Indian Subcontinent. J Assoc Physicians India. 2020;68(7):13-18.

6. Romero Starke K, Petereit-Haack G, Schubert M, Kämpf D, Schliebner A, Hegewald J, et al. The Age-Related Risk of Severe Outcomes Due to COVID-19 Infection: A Rapid Review, MetaAnalysis, and Meta-Regression. Int J Environ Res Public Health. 2020; 17(16): 5974.

https://doi.org/10.3390/ijerph17165974

7. Bonanad C, García-Blas S, Tarazona-Santabalbina F, Sanchis J, Bertomeu-González V, Fácila L, et al. The Effect of age on Mortality in Patients With COVID-19: A Meta-Analysis With 611,583 Subjects. Journal of the American Medical Directors Association. 2020;21(7):915-918. https://doi.org/10.1016/j.jamda.2020.05.045

8. Zhang B, Zhou X, Qiu Y, Song Y, Feng F, Feng J, et al. Clinical characteristics of 82 cases of death from COVID-19. PLoS ONE. 2020;15(7):e0235458.

https://doi.org/10.1371/journal.pone.0235458

9. Gupta N, Agrawal S, Ish P, Mishra S, Gaind R, Usha G, et al. Clinical and epidemiologic profile of the initial COVID-19 patients at a tertiary care centre in India. Monaldi Archives for Chest Disease. 2020;90(1). https://doi.org/10.4081/monaldi.2020.1294

10. Burugu H, Kandi V, Kutikuppala LVS and Suvvari TK. Activities of Serum Ferritin and Treatment Outcomes Among COVID-19 Patients Treated with Vitamin C and Dexamethasone: An Uncontrolled Single-Center Observational Study. Cureus. 2020;12(11): e11442.

https://doi.org/10.7759/cureus.11442

11. Singh AK and Misra A. Impact of COVID-19 and comorbidities on health and economics: Focus on developing countries and India. Diabetes Metab Syndr. 2020;14(6):1625-1630. https://doi.org/10.1016/j.dsx.2020.08.032

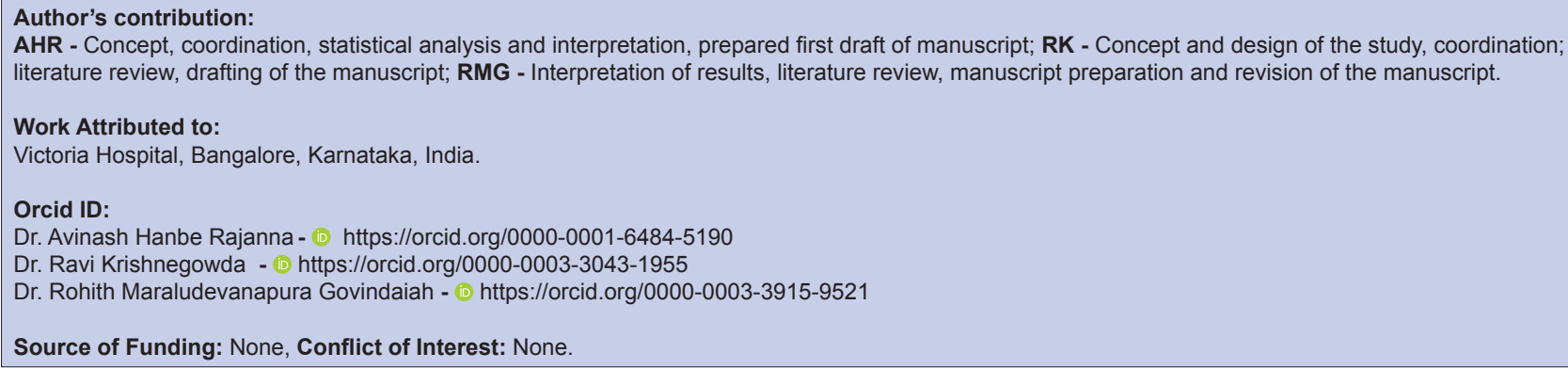

